University for Business and Technology in Kosovo

UBT Knowledge Center

Nov 7th, 9:00 AM - 5:00 PM

\title{
Motorizing CBD of Tirana. A Before and After Study in Tirana from Sustainability Point of View
}

\author{
Edison Barhani \\ Epoka University, barhani.edison@gmail.com
}

Follow this and additional works at: https://knowledgecenter.ubt-uni.net/conference

Part of the Civil Engineering Commons, and the Structural Engineering Commons

\section{Recommended Citation}

Barhani, Edison, "Motorizing CBD of Tirana. A Before and After Study in Tirana from Sustainability Point of View" (2015). UBT International Conference. 81.

https://knowledgecenter.ubt-uni.net/conference/2015/all-events/81

This Event is brought to you for free and open access by the Publication and Journals at UBT Knowledge Center. It has been accepted for inclusion in UBT International Conference by an authorized administrator of UBT Knowledge Center. For more information, please contact knowledge.center@ubt-uni.net. 


\title{
Motorizing CBD of Tirana. A Before and After Study in Tirana from Sustainability Point of View
}

\author{
Edison Barhani ${ }^{1}$ \\ ${ }^{1}$ Epoka Univeristy, Rr. Autostrada Tiranë-Rinas, km. 12, 1000, Tirana, \\ barhani.edison@gmail.com
}

\begin{abstract}
The Center Business District of Tirana (Skanderbeg Square) plays a crucial part in Tirana Transportation Sy stem. After a closure of about 2 years, being under reconstruction, CBD opened to traffic on November 14th, 2011. This study analy ses performance parameters like: travel time for both cars and buses, waiting time at bus stations, and passenger boarding/alignment for bus passing through or around the CBD before and after it was opened to traffic. Route that follows Kinostudio-Kombinat bus line has been selected as a representative of all other lines passing through the center of Tirana. Opened to traffic for the supply to meet the demand differently with sustainability approaches, this significant structural change in transportation system of Tirana has deteriorated the total transportation sy stem of Tirana City. Higher travel speeds were observed within CBD but slower ones out of it. In addition, although this change has led to a slight improvement in east part of Tirana, travel speeds at the west part which is a main entrance to Tirana of intercity commuters has been significantly deteriorated (20-25\%). Moreover, this change indirectly has changed flow distribution at signalized intersections thus making the system less efficient. Last but not least, capacity of public transport services has not been increased to cope with the increase of number of public transport commuters, hence making the mode less attractive. Providing the supply to meet the demand is not anymore the solution, but the sustainability is permanent solution.
\end{abstract}

Keywords: Public transport, Sustainability, Travel speed, Passenger accumulation

\section{Introduction}

Tirana as Albanian Capital city has rapidly developed last two decades. Tirana population (city only) doubled approximately every decade and according to Census 2011 536,998 inhabitants lives in Tirana (Instat, 2012). The same data source revealed that the number of dwellings have increased by $67 \%$ during the last decade. In reply, Tirana Municipality has been continuously investing in its transportation systems by constructing now roads, widening the existing roads and maintaining them. The same solution, where supply has to be increased to meet the demand, was decided by the new Mayer in 2011 by changing the plan of the CBD from car-free to an automobile oriented one.

This decision has pushed away the principals of sustainable transportation as the better solution in these typical circumstances. Litman (2003) in his study indicated that road widening is not a solution for decreasing the congestion level. However, improving public transport and designing High Occupancy Vehicle (HOV) lanes decrease the congestion level. On the other hand, European Conference of Ministers of Transport (ECMT 2004) defines the sustainable transport system as one that is accessible, safe, environmentally-friendly, and affordable. In Europe a majority of citizens are calling for changes to promote modes of transport which are more respectful of their environment (European Commission - Eurobarometer). Sustainable transport should be the use of transport and other factors in helping to meet present needs without jeopardizing future generations (White Paper, 2001). When the roads under consideration are already highly congested, it is typically assumed that reducing the capacity available for cars will result in increased traffic congestion in the surrounding streets. However, as the evidence in the previous applications this is not necessarily the case. Some pioneering cities, for example Copenhagen in Denmark, have adopted such a policy for many years with great success (Gehl and Gemzøe, 1996). There is a growing body of evidence that where wellplanned measures to reduce road space for private cars are implemented in congested areas and where 
no alternative network capacity is available, over the long term the predicted traffic chaos does not occur (Cairns at al., 1998).

\section{Study Area and Data Collection}

The purpose of this study was to measure and compare performance parameters like: travel time for both cars and buses, waiting time at bus stations, and passenger boardings/alignments for bus passing through or around the CBD before and after it was opened to traffic.

Skanderbeg square is Tirana's most important square, where most of the governmental buildings, national museum and historic buildings are located around. This center has been under construction for more than two years in compliance with the plan considering it a fully pedestrianized and a carfree square. However, this plan was suddenly changed in 2011, making this square again motorized. The car-free area was measured to be $200,000 \mathrm{~m} 2$, later decreased to $16,000 \mathrm{~m} 2$, almost not usable by pedestrians serving only like a roundabout after it was open to the traffic.

Bus line from Kombinat to Kinostudio (Fig. 1) was considered to be a representative line for other ones passing through this center. The length of this line is about $8.7 \mathrm{~km}$ (shortenend to $8.4 \mathrm{~km}$ ) and comprised 17 bus stations. The roads where buses travel vary from arterials to collectors and from two to six lanes, with and/or without street parking. They travel through commercial, industrial, residential, and through the Skanderbeg Square.

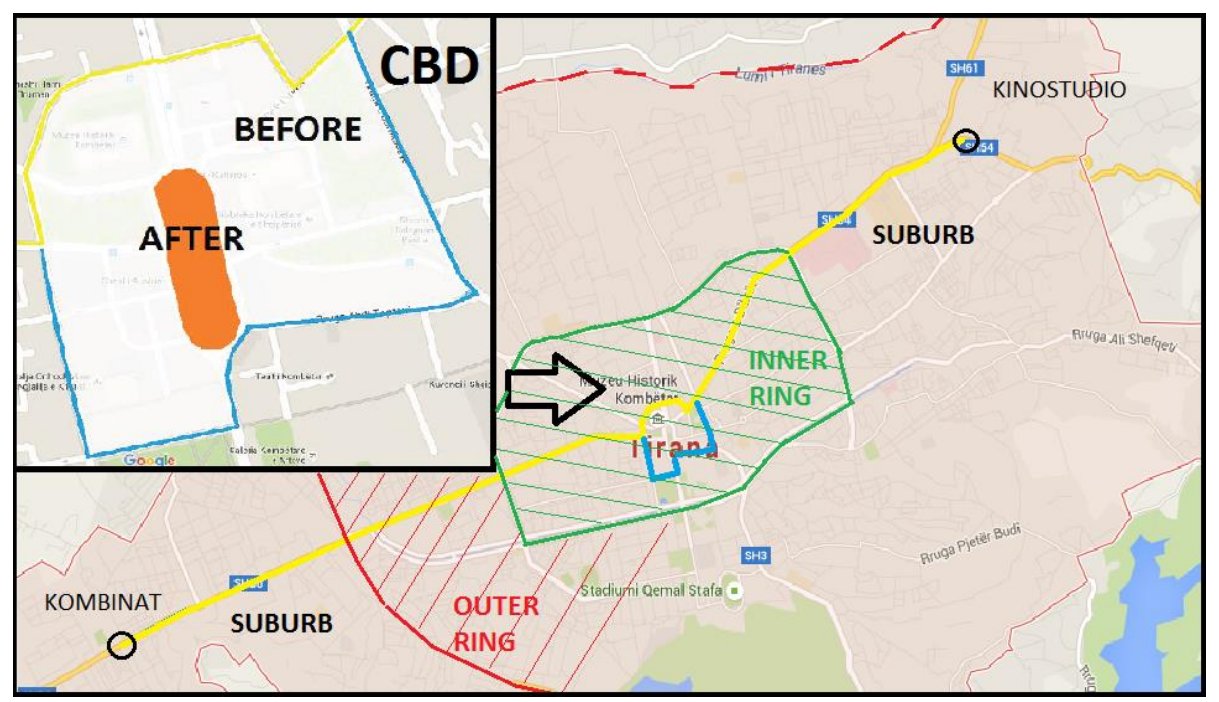

Fig. 1. Study area; Kombinat-Kinostudio bus route.

Teams of two people collected data by driving buses during randomly selected times of the day starting from 7:00 till 19:00. Bus operation characteristics; travel times, stop time in the bus station, boarding and alignment of passengers' information were collected manually for each direction at each bus station. At the same time, two cars have been driven through the same route in both directions and time incremental for each station was measured. Distance from each station was obtained from topographical maps. All the data were collected within three days from Tuesday to Thursday and the weather was cloudy. The same measurements were conducted after the opening to traffic of CBD almost two years latter to avoid any bias; again within three days from Tuesday to Thursday where the weather conditions were the same and traffic characteristics were considered adjusted. 


\section{Analysis and Discussion}

Travel speed of the bus is one of the most important indications of the level of service of the transit operation. The data collected on the field were processed and summarized in Fig. 2 and Fig. 3 showing the travel speeds for buses and cars before and after CBD was opened to the traffic.

Apparently travel speed of the bus within the CBD has increased from $11 \mathrm{~km} / \mathrm{hr}$ to $15 \mathrm{~km} / \mathrm{h}$ in the west direction and $10 \mathrm{~km} / \mathrm{hr}$ to $13 \mathrm{~km} / \mathrm{h}$ in east direction. In addition, improvement was done for auto mode in the east direction (from $12 \mathrm{~km} / \mathrm{h}$ to $18 \mathrm{~km} / \mathrm{h}$ ); whereas in the west direction was not $(12 \mathrm{~km} / \mathrm{h})$. This may have resulted because the automobiles had to use the same route as before in the west direction. Interesting figures were observed out of the CBD area. Opening to traffic the CBD has led to an improvement of travel speed in the east part of Tirana for all modes. On the other hand, the situation in west side of Tirana has been deteriorated. The travel speeds has been decreased probably because people coming from east part, which is a main entrance to Tirana, has found traveling through CBD more attractive especially for commuters from long distances (inter city). Previously, these commuters had only public transport option to travel to and/or back from CBD. In addition, currently they are less sensitive to extra traveling costs within the CBD and thus chose automobile mode rather than bus mode.

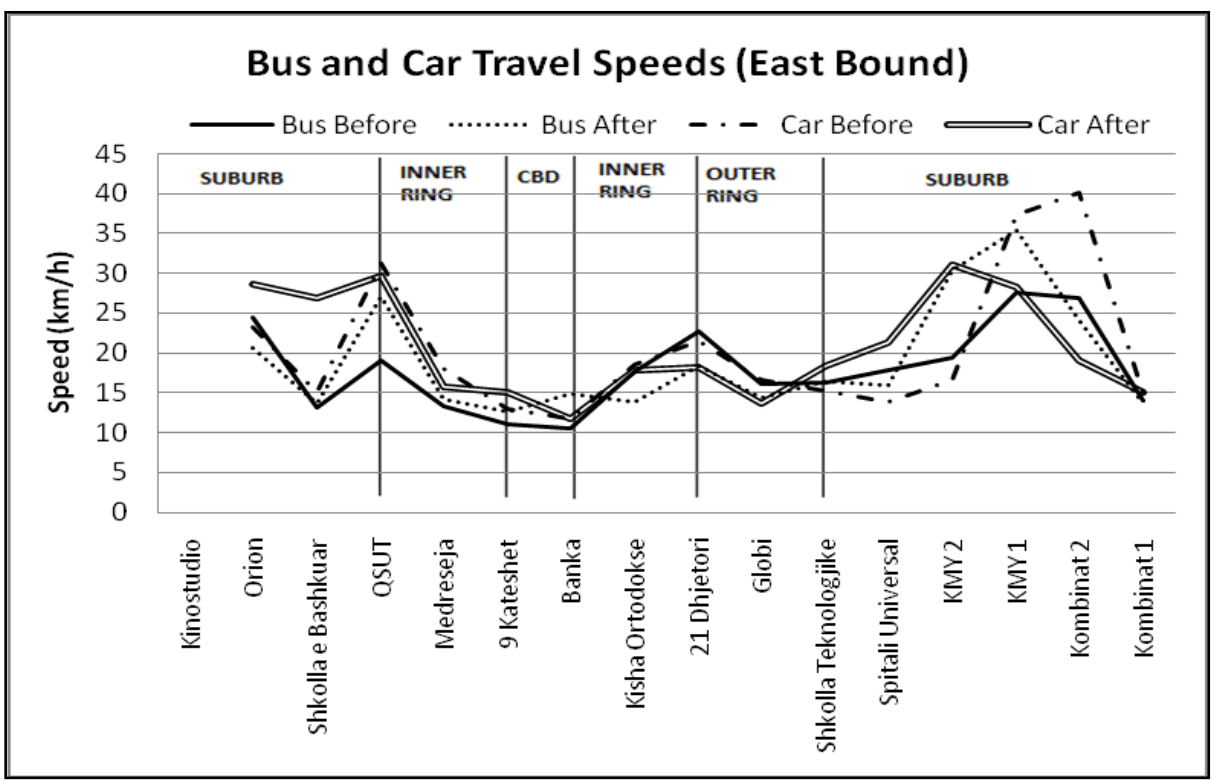

Fig. 2. Travel time of bus and car before and after (Kinostudio-Kombinat - west direction)

Moreover, this significant change in travel speeds, directly affect traffic light signalization timing which need to be re-optimized. Furthermore, parking demand is expected to have been increased in the vicinity of the $\mathrm{CBD}$, hence slowing down the traffic flow by increasing flow friction.

Fig. 4 shows average passenger accumulation per trip. The maximum accumulation of 80 passengers is reached at Bank Bus Station, for the west direction. On the other hand, the maximum accumulation of 82 passengers is reached at 21dhjetori bus station for the east direction. It should be noted that the number of the passengers in the east direction has been increased for the east direction from 60 to 82 . 


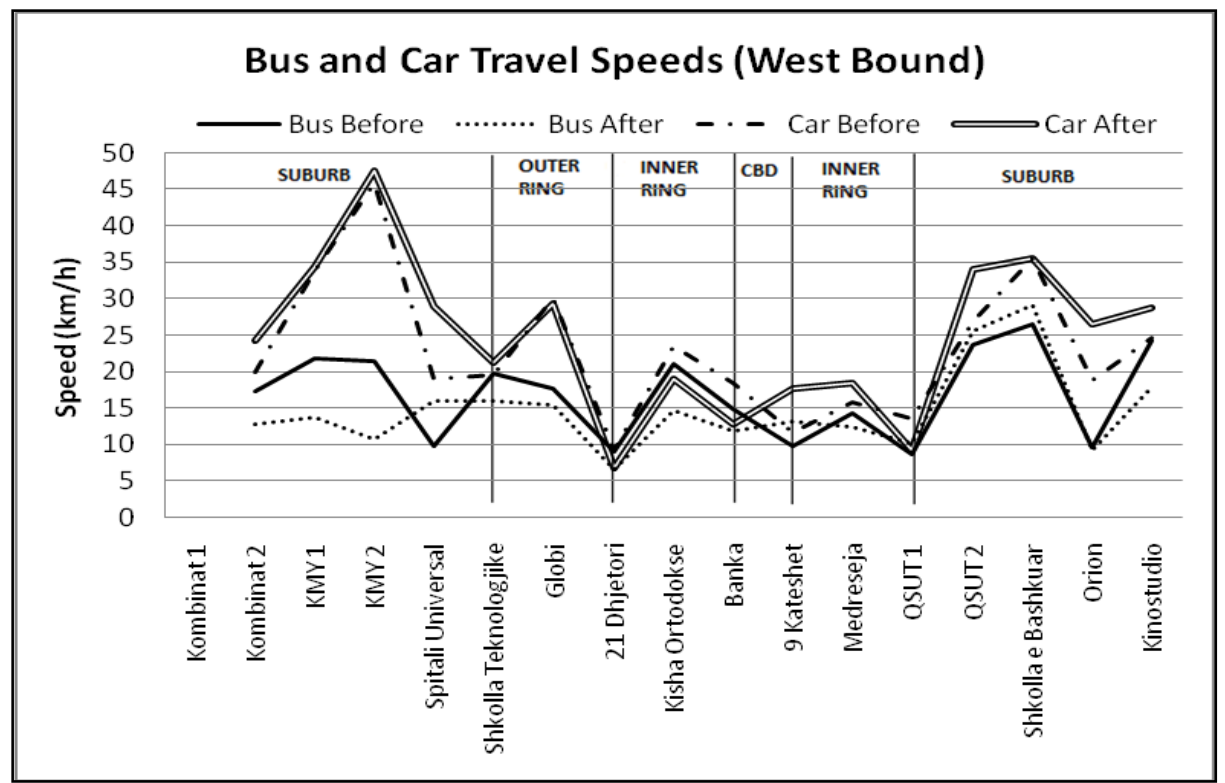

Fig. 3. Travel time of bus and car before and after (Kombinat-Kinostudio - east direction)

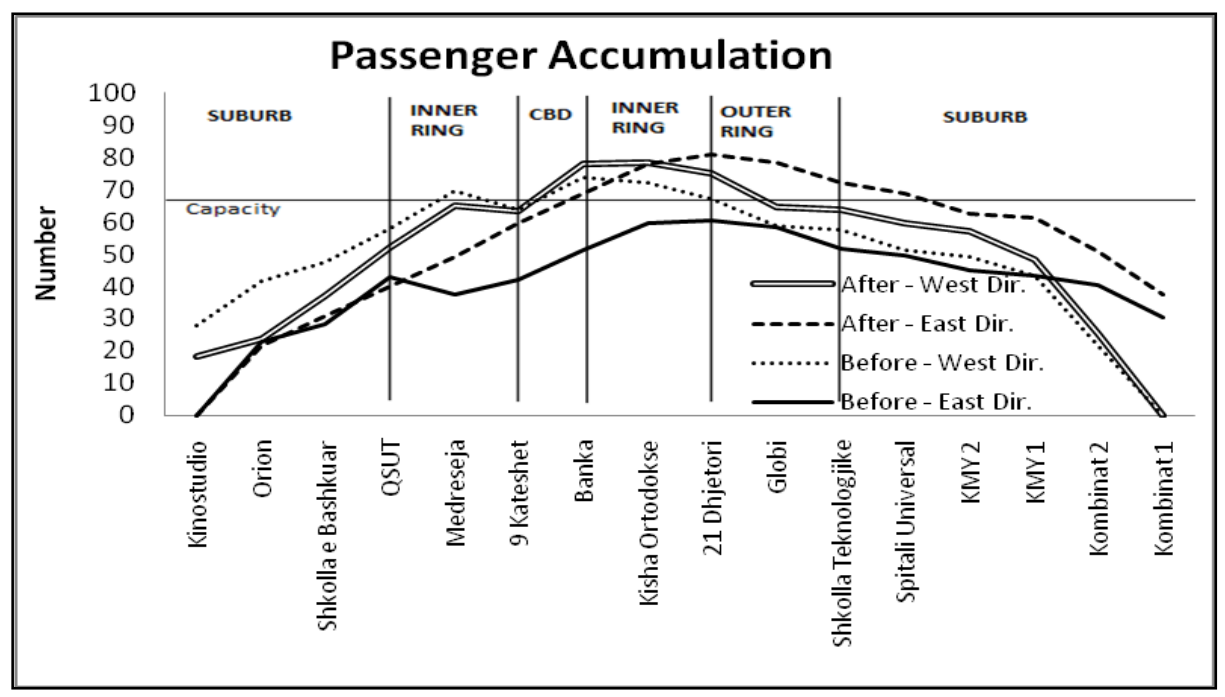

Fig. 4. Passenger Accumulation

The bell shape of the distribution shows that most of the passengers come into the Square for different purposes from both directions. As a result of this ty pe of distribution bus stations near the square serve as terminal stations. Adding another line from Medresea to Shkolla Teknologike would have improved the comfort of public transportation mode, thus making it more attractive.

In addition, the maximum number of passengers at the same time in the bus has been measured to be 82. This is standard type bus is designed to carry about 60-65 passengers. This high number of passengers above the bus capacity shows that a lot of people are using the bus mode. However, nothing is done to increase the caring capacities of mass transportation, making this mode less comfortable.

Moreover, the longest waitingtime is observed in Bank station; appearantly showing that this station is used as a terminal station or for schedule adjusting purposes. This situation discourages bus users. 


\section{Conclusions and Recommendations}

Benefits of creating additional road capacity are not as significant as it was previously believed, (Litman, 2003). The road widening is not a solution for decreasing the congestion level. The actual transportation system in Tirana does not take into account the fundamentals of the sustainability. Therefore, the need for a detailed and comprehensive transport policy, to encourage sustainable transport and sustainable mobility, is essential and crucial. The increase of road capacity in the center has improved the travel speed within the square. However, travel speeds in west side significantly deteriorated whereas in east side has been slightly improved. The longest waiting time is observed in Bank station; appearantly showing that this station is used as a terminal station or for schedule adjusting purposes. This situation discourages bus users. A high number of passengers above the bus capacity observed during this study shows that even though people are using bus mode nothing seem to have been done to increase the carrying capacities of mass transportation. This situation forces passengers to use other modes of transportation like passenger cars minibuses.

\section{References}

1. McKnight E. C., Levinson S. H., Ozbay K., Kamga C., Paaswell E. R., The Impact of Traffic Congestion on Bus Travel Time in Northern New Jersey, 2004

2. Bertini L. R., and El-Geneidy M. A., Modeling Transit Trip Time Using Archived Bus Dispatch System Data, 2002

3. Buehler R., and Pucher J., Sustainable Transport in Freiburg: Lessons from Germany's Environmental Capital, International Journal of Sustainable Transportation, 5:43-70, 2011

4. M. El-Geneidy A, Hourdos J., Horning J., Bus Transit Service Planning and Operations in a Competitive Environment, Journal of Public Transportation, Vol. 12, No. 3, 2009

5. Vuchic R. V., Urban Transit Operations, Planning and Economics, John Wiley \& Sons, 2005 